\title{
A Prospective study on Gastrointestinal Perforation Peritonitis in Andhra Pradesh, India
}

\author{
Rao G. ${ }^{1}$, Rao B. ${ }^{2 *}$ \\ DOI: https://doi.org/10.17511/ijoso.2020.i05.08 \\ ${ }^{1}$ G. Someswara Rao, Associate Professor, Department of General Surgery, Great Eastern Medical School and Hospital, Srikakulam, Andhra \\ Pradesh, India.

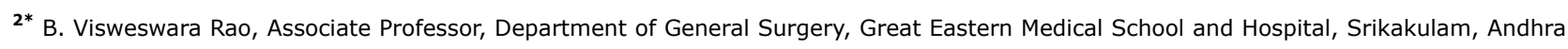 \\ Pradesh, India.
}

Introduction: Perforation is defined as an abnormal opening in a hollow organ or viscus. All over the world, perforation peritonitis is the most prevalent surgical emergency tackled and treated by a surgical team. The etiology leading to peritonitis in tropical countries shows a different spectrum from its western world. The present study was conducted to highlight the spectrum of hollow viscus perforation peritonitis in terms of etiology, clinical presentations, site of perforation, surgical treatment, postoperative complications, and mortality encountered. Methods: The study was a prospective observational study conducted from March 2016 to March 2019 in the Department of General Surgery, Great Eastern Medical School and Hospital, Andhra Pradesh. A total of 320 patients with perforation peritonitis were included in the study and underwent exploratory laparotomy. Results: Out of 320 patients, there were 276 males (86.25\%) and 44 females (13.75\%). Duodenal perforation was the most common type (34.38\%), which was mainly due to Acid peptic disease followed by Jejunal and Ileal perforations. Wound infection was the most common complication. The mortality rate was $8.44 \%$ (27 patients). Conclusion: Early diagnosis, resuscitation with fluids, and timely surgical intervention are the most important factors deciding the fate of the patient with perforation peritonitis.

Keywords: Perforation, Peritonitis, Laparotomy, Gastrointestinal, Andhra Pradesh

Corresponding Author

B. Visweswara Rao, Associate Professor, Department of General Surgery, Great Eastern Medical School and Hospital, Srikakulam, Andhra Pradesh, India. Email: drgudenasomeswararao@gmail.com
How to Cite this Article

To Browse

Rao GS, Rao BV. A Prospective study on

Gastrointestinal Perforation Peritonitis in Andhra

Pradesh, India. Surgical Rev Int J Surg Trauma

Orthoped. 2020;6(5):333-337.

Available From

https://surgical.medresearch.in/index.php/ijoso/artic le/view/209

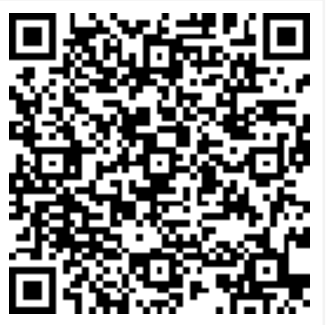




\section{Introduction}

Generalized peritonitis as a result of gastrointestinal perforation is a common surgical emergency in India [1]. Despite advances in perioperative care, antimicrobial therapy, and intensive care support, perforation peritonitis still has high morbidity and mortality [2-3].

Perforation is defined as an abnormal opening in a hollow organ or viscus. It is derived from the Latin perforatus, meaning "to bore through."

Left untreated, peritonitis can rapidly spread into the blood (sepsis) and to other organs, resulting in multiple organ failure and death.

The spectrum of gastrointestinal perforation is having wide-geographical variations; in western countries with a preponderance of lower gastrointestinal perforations as opposed to upper gastrointestinal perforations in developing countries $[4,5]$.

The spectrum of etiology of perforation is different between developing and developed countries $[6,7]$ and there are a paucity of data from India regarding its etiology, prognostic indicators, morbidity, and mortality patterns [8].

The present study was conducted to highlight the spectrum of hollow viscus perforation peritonitis in terms of etiology, clinical presentations, site of perforation, surgical treatment, postoperative complications, and mortality encountered at Great Eastern Medical School and Hospital, Andhra Pradesh.

\section{Methods}

Type of study and Study Setting: A hospitalbased prospective study conducted in the Department of General Surgery, Great Eastern Medical School and Hospital, Srikakulam, Andhra Pradesh.

Duration of the study: ; March 2016 to March 2019

Sample Size: 320 cases who presented to the emergency department and received a diagnosis of perforation peritonitis.

Inclusion criteria: All cases found to have peritonitis as a result of perforation in any part of the gastrointestinal tract at the time of surgery were included in the study.
Exclusion criteria: Patients presenting with the esophagus, pancreaticobiliary tree, or genitourinary tract perforation or undergoing laparotomy for primary peritonitis, tertiary peritonitis (anastomotic leak and fecal fistula), or pancreatitis

Data collection and procedures: All patients were evaluated for their presentation to the surgeon, radiological/sonological investigations done, etiology of perforation, and site of perforation, postoperative morbidity, and mortality. After establishing the clinical diagnosis of peritonitis secondary to perforation, all patients were resuscitated and simultaneously prepared for surgery after preoperative antibiotic prophylaxis with a broadspectrum drug.

All patients underwent emergency exploratory laparotomy. After opening the abdomen, the source of peritonitis was located and controlled, with an adequate procedure. The abdomen was washed with 5 to 8 liters of warm normal saline, drains were placed in the general peritoneal cavity, and the abdomen closed with non-absorbable number 1 suture.

All Patients were followed in the postoperative ward or ICU (intensive care unit) with the cover of broadspectrum antibiotics along with fluid and electrolyte balance.

Statistical analysis: All data related to the patient from admission to discharge was collected in a proforma after taking written consent. Data were analyzed using SPSS software version 17, and values are presented in numbers and percentages.

\section{Results}

There was a total of 276 male (86.25\%) and 44 female $(13.75 \%)$ patients in the present study (Table 1). In the present study, all the patients had pain abdomen $(100 \%)$, followed by abdomen distension (93.75\%), constipation (90.63\%) and vomiting was present in $26.25 \%$ of cases (Table 2 ).

According to the site, gastric and prepyloric perforations comprised $(18.13 \%)$ cases, while duodenal perforation was the most common type (34.38\%) (Table 4), which were mainly due to Acid peptic disease $(48.75 \%)$, Jejunal and Ileal perforations $(33.45 \%)$ were due to typhoid, tuberculosis, and trauma. Appendicular perforations $(11.25 \%)$ were the result of Acute appendicitis and large bowel perforations can be due to Malignancy or trauma (Table 4). 
In the study, a variety of operative procedures were performed depending on the patients' general condition, peritoneal contamination, site of perforation, gut viability, and surgeons' decision [Table 3].

The most commonly executed operative procedure was the simple closure of perforation either in a single or in a double layer in $65.3 \%$ of cases (Table $5)$.

In the present series, wound infection was the most common complication in $88(27.5 \%)$, followed by pulmonary complications in $74(23.13 \%)$, wound dehiscence in 26 cases (8.13\%).

Electrolyte imbalances were seen in $10.63 \%$ of cases. Postoperative leak seen in 11 cases. In the present study, the mortality rate was $8.44 \%$ ( 27 patients). Mortality was more in patients of $61-80$ years of age (Table 6).

Table 1: Gender distribution.

\begin{tabular}{|l|l|l|}
\hline \multicolumn{1}{|c|}{ Gender } & \multicolumn{1}{|c|}{ No. of patients } & \multicolumn{1}{c|}{ Percentage (\%) } \\
\hline Male & 276 & 86.25 \\
\hline Female & 44 & 13.75 \\
\hline Total & 320 & 100 \\
\hline
\end{tabular}

Table 2: Chief complaints.

\begin{tabular}{|l|l|l|}
\hline \multicolumn{1}{|c|}{ Complaint } & No. of patients & \multicolumn{1}{c|}{ Percentage (\%) } \\
\hline Pain in abdomen & 320 & 100 \\
\hline Abdominal distension & 300 & 93.75 \\
\hline Constipation & 290 & 90.63 \\
\hline Vomiting & 84 & 26.25 \\
\hline Diarrhoea & 8 & 2.5 \\
\hline Fever & 132 & 41.25 \\
\hline
\end{tabular}

Table 3: Cause of perforation.

\begin{tabular}{|l|l|l|}
\hline \multicolumn{1}{|c|}{ Cause } & No. of patients & Percentage (\%) \\
\hline Acid peptic disease & 156 & 48.75 \\
\hline Appendicitis & 34 & 10.63 \\
\hline Typhoid & 39 & 12.19 \\
\hline Tuberculosis & 35 & 10.94 \\
\hline Trauma & 41 & 12.81 \\
\hline Malignancy & 4 & 1.25 \\
\hline Strangulation of bowel & 11 & 3.44 \\
\hline
\end{tabular}

Table 4: Site of perforation.

\begin{tabular}{|l|l|l|}
\hline \multicolumn{1}{|c|}{ Site } & No. of patients & Percentage (\%) \\
\hline Gastric and prepyloric & 58 & 18.13 \\
\hline Duodenum & 110 & 34.38 \\
\hline Jejunum & 15 & 4.68 \\
\hline Ileum & 92 & 28.75 \\
\hline Appendix & 36 & 11.25 \\
\hline Colon and rectum & 9 & 2.81 \\
\hline
\end{tabular}

Table 5: Operative procedure performed.

\begin{tabular}{|l|l|l|}
\hline \multicolumn{1}{|c|}{ Operative procedure } & No. of patients & Percentage (\%) \\
\hline Simple closure* & 209 & 65.3 \\
\hline Stoma formation** & 46 & 14.38 \\
\hline Appendectomy & 36 & 11.25 \\
\hline Resection anastomosis & 19 & 5.94 \\
\hline Definitive procedure*** & 10 & 3.13 \\
\hline Total & 320 & 100 \\
\hline
\end{tabular}

*Simple closure: Simple closure with or without omental patch/FJ/GJ,

**Stoma formation: Simple closure/resection anastomosis with diversion ileostomy/colostomy/resection with end stoma with distal mucous fistula/exteriorization of perforation as stoma,

$* * *$ Definitive procedure: Billroth type I/II, right/left hemicolectomy, pancreaticoduodenectomy with GJ/FJ/HJ/PJ. FJ: Feeding jejunostomy, GJ: Gastrojejunostomy, HJ: Hepaticojejunostomy, PJ: Pancraticojejunostomy

Table 6: Complications.

\begin{tabular}{|l|l|l|}
\hline \multicolumn{1}{|c|}{ Complication } & No. of patients & Percentage (\%) \\
\hline Wound infection & 88 & 27.5 \\
\hline Respiratory complications & 74 & 23.13 \\
\hline Dyselectrolytaemia & 34 & 10.63 \\
\hline Abdominal collection & 21 & 6.56 \\
\hline Wound dehiscence & 26 & 8.13 \\
\hline Leak & 11 & 3.43 \\
\hline Mortality & 27 & 8.44 \\
\hline
\end{tabular}

\section{Discussion}

In the present study among 320 patients, $86.25 \%$ (276) of them were males and $13.75 \%$ (44) of them were females. All types of perforation occurred more frequently in male patients. All studies related to perforation peritonitis show a male preponderance, although the male-to-female ratio varies from $1.34: 1$ to $7: 1[2,7,9-12]$. A possible reason for this finding may be smoking and alcohol intake, which is more frequent among men, thus increasing the risk of perforation.

In all types of perforations, patients were reported more in the $<50$ years' age group except in the malignant type of perforation where it was more in $>50$ years' age group. Similar observations were found by Jhobta et al [7] Gupta et al [11] and Ramakrishnaiah et al [12]. This finding is in contrast to studies in the Western countries where perforation primarily occurs in the elderly [13]. 
This is related due to the difference in the etiology. The Western literature suggests that foreign body, ischemia, radiotherapy, diverticula, Crohn's disease, etc. are the main causes of perforation, which are more commonly seen in elderly patients.

In contrast to this, infection is the most common cause of perforations in developing countries. This includes acid peptic ulcer disease related to Helicobacter pylori infection, typhoid fever, and tuberculosis, which are quite common in the young [9,14-16].

Abdominal pain was noted in all patients presenting with perforation followed by distension in $93.75 \%$ and constipation in $90.63 \%$. Vomiting was significantly more common in appendicular and strangulation type. Diarrhea was significantly more common in the appendicular type, while fever was significantly more commonly observed in appendicular and enteric perforations.

Pain abdomen was the universal presenting symptom in other studies on perforation $[11,12]$, Jhobta et al [7] found abdominal pain in $98 \%$, while Afridi et al [17] reported a similar history in $78 \%$ of patients. Clinical presentation of the patients varied according to the site and cause of perforation.

According to personal history, in the present study, NSAID usage was observed more in strangulation type, acid peptic ulcer disease, and enteric perforation patients. Higher NSAID intake in peptic ulcer diseases is for treatment of some other pain, while in enteric fever, it was for management of fever.

The proportion of the patients who had a history of chronic smoking was more in peptic perforation followed by strangulation. Alcohol users were more exposed to the traumatic type of perforation because of the higher risk of road traffic accidents and assaults. All these findings were found significant.

In the present study, a variety of operative procedures were adopted depending on the patients' general condition, peritoneal contamination, site of perforation, gut viability, and surgeon's decision.

The most commonly executed operative procedure was simple closure in $65.3 \%$ cases of the perforation, resection anastomosis in $5.94 \%$, stoma in $14.38 \%$, appendicectomy in $11.25 \%$, and definitive procedure in $3.13 \%$.
Similar observations were noted by Jhobta et al [7] with simple closure being the most commonly executed operative procedure in $60 \%$ of patients.

In the present study, Wound infection was the most commonly observed postoperative complication followed by a Lung infection. Similar observations were made by Afridi et al [17] while Jhobta et al [7] found Lung infection to be the most common complication.

In the present study, the mortality rate was $8.44 \%$ (27 patients). Mortality was more in patients of 6180 years of age which is similar to Chalya et al and Goud et al as patients in this age group have poor nutritional status and associated comorbidities $[18,19]$.

\section{Conclusion}

Peptic ulcer disease leading to perforation, perforated appendicitis, typhoid, and tubercular perforations are the commonest causes of gastrointestinal perforations.

\section{What does the study add to the existing knowledge}

Early diagnosis, resuscitation with fluids, and timely surgical intervention are the most important factors deciding the fate of the patient with perforation peritonitis.

\section{Author's contribution}

Dr. G. Someswara Rao: Concept, study design

Dr. B. Visweswara Rao: Manuscript preparation

\section{Reference}

01. Ramakrishnan K, Salinas RC. Peptic ulcer disease. Am Fam Physician. 2007;76(7)1005-

12.

[Crossref]

02. Agarwal N, Saha S, Srivastava A, Chumber S, Dhar A, Garg S. Peritonitis- 10 years' experience in a single surgical unit. Trop Gastroenterol. 2007;28(3)117-120.

[Crossref]

03. Gupta S, Kaushik R. Peritonitis - The Eastern experience. World J Emerg Surg. 2006;1;13.

doi: $10.1186 / 1749-7922-1-13$ [Crossref] 
04. Malangoni MA, Inui T. Peritonitis - the Western experience. World J Emerg Surg. 2006;1;25.

doi: $10.1186 / 1749-7922-1-25$ [Crossref]

05. Afridi SP, Malik F, Ur-Rahman S, Shamim S, Samo KA. Spectrum of perforation peritonitis in Pakistan- ses Eastern experience. World J Emerg Surg. 2008;3;31.

doi: $10.1186 / 1749-7922-3-31$ [Crossref]

06. Dorairajan LN, Gupta S, Deo SV, Chumber S, Sharma LK. Peritonitis in India - A decade's experience. Trop Gastroenterol. 1995;16(1)3338.

[Crossref]

07. Jhobta RS, Attri AK, Kaushik R, Sharma R, Jhobta A. Spectrum of perforation peritonitis in India - Review of 504 consecutive cases. World J Emerg Surg. $2006 ; 1 ; 26$.

doi: $10.1186 / 1749-7922-1-26$ [Crossref]

08. Sharma L, Gupta S, Soin AS, Sikora S, Kapoor V. Generalized peritonitis in India - The tropical spectrum. Jpn J Surg. 1991;21(3)272-277.

doi: $10.1007 / B F 02470946$ [Crossref]

09. Mahajan G, Kotru M, Sharma R, Sharma S. Usefulness of histopathological examination in nontraumatic perforation of smallintestine. J Gastrointest Surg. 2011;15(10)1837-41.

doi: $\quad 10.1007 / s 11605-011-1646-z \quad$ [Crossref]

10. Jain BK, Arora H, Srivastava UK, Mohanty D, Garg PK. Insight into the management of nontraumatic perforation of the small intestine. J Infect Dev Ctries. 2010;4(10)650-654.

doi: $10.3855 /$ jidc. 829 [Crossref]

11. Gupta SK, Gupta R, Singh G, Gupta S. Perforation peritonitis- A two year experience. JK Sci. 2010;12(3)141-144.

[Crossref]

12. Ramakrishnaiah VP, Chandrakasan C, Dharanipragadha K, Sistla S, Krishnamachari S. Community acquired secondary bacterial peritonitis in a tertiary hospital of South IndiaAn audit with special reference to peritoneal fluid culture. Trop Gastroenterol. $2012 ; 33(4) 275-281$.

doi: $\quad 10.7869 / \mathrm{tg} .2012 .70 \quad$ [Crossref]
13. Svanes C, Salvesen H, Espehaug B, Søreide O, Svanes K. A multifactorial analysis of factors related to lethality after treatment of perforated gastroduodenal ulcer 1935-1985. Ann Surg. $1989 ; 209(4) 418-423$.

doi: $10.1097 / 00000658-198904000-00005$ [Crossref]

14. Wani RA, Parray FQ, Bhat NA, Wani MA, Bhat $\mathrm{TH}$, Farzana F. Nontraumatic terminal ileal perforation. World J Emerg Surg. $2006 ; 1 ; 7$. doi: $10.1186 / 1749-7922-1-7$ [Crossref]

15. Kimchi NA, Broide E, Shapiro M, Scapa E. Nontraumatic perforation of the small intestine, Report of 13 cases and review of the literature. Hepatogastroenterology. 2002;49(46)10171222.

[Crossref]

16. Sharma MP, Bhatia V. Abdominal tuberculosis. Indian J Med Res. 2004;120(4):305-315.

[Crossref]

17. Afridi SP, Malik F, Ur-Rahman S, Shamim S, Samo KA. Spectrum of perforation peritonitis in Pakistan: 300 cases Eastern experience. World J Emerg Surg. 2008;3:31.

doi: $10.1186 / 1749-7922-3-31$ [Crossref]

18. Chalya P, Mabula JB, Koy M, Mchembe MD, Jaka $H M$, Kabangila $R$, et al. Clinical profile and outcome of surgical treatment of perforated peptic ulcers in Northwestern Tanzania- A tertiary hospital experience. World J Emerg Surg. $2011 ; 6 ; 31$.

doi: $10.1186 / 1749-7922-6-31$ [Crossref]

19. Goud VS, Babu NV, Kumar PB. Comparative Study of Closure of Duodenal Perforations with Omental Plugging Versus Graham's Patch. Int ] Sci Stud. 2016;4(8)138-142.

doi: $10.17354 /$ ijss/2016/585 [Crossref] 